\title{
PAPERS
}

\section{Mucosal reactive oxygen species production in oesophagitis and Barrett's oesophagus}

\author{
M Olyaee, S Sontag, W Salman, T Schnell, S Mobarhan, D Eiznhamer,
} A Keshavarzian

\begin{abstract}
Reactive oxygen species (ROS) produced by inflammatory cells can contribute to tissue destruction. ROS have been implicated in various gastrointestinal abnormalities, including the acid related peptic diseases. Although the development of oesophagitis and Barrett's columnar epithelium is associated with prolonged reflux of gastric acid, the exact mechanism by which tissue damage occurs is not known. To discover if $\mathrm{ROS}$ are involved in damage to the oesophageal mucosa, this study measured in vitro the mucosal ROS concentrations of biopsied mucosal samples taken from patients with reflux oesophagitis using luminol enhanced chemiluminescence (LECL). Mucosal biopsy specimens were taken from 83 patients: 19 with normal oesophageal mucosa (group I); 20 with macroscopic oesophagitis (group II); 20 with biopsy confirmed Barrett's epithelium without macroscopic oesophagitis (group III); and 24 with Barrett's epithelium with macroscopic oesophagitis (group IV). The mucosa from patients exhibited significantly higher LECL values than the mucosa from controls. But, there were no significant differences between groups II, III, and IV. Addition of the myeloperoxidase inhibitor, azide, or the hydrogen peroxide scavenger, catalase, to the tissue suspension caused a decrease in LECL values of $32 \%$ and $45 \%$, respectively, suggesting that neutrophils - although important - are not the only source of mucosal LECL. These data are consistent with the proposal that ROS play an important part in the tissue injury associated with oesophagitis and Barrett's columnar epithelium. (Gut 1995; 37: 168-173)
\end{abstract}

Keywords: Barrett's oesophagus, oesophagitis, reactive oxygen species, oxygen free radicals, chemiluminescence, oesophageal cancer.
Oesophagitis and the pre-malignant condition of Barrett's oesophageal epithelium are common sequelae of gastro-oesophageal reflux. ${ }^{1}$ Although reflux of gastric acid is the single most important initiating factor in the development of oesophagitis and subsequent Barrett's oesophagus, ${ }^{2} 3$ the mechanism by which tissue injury occurs is not fully understood. Reactive oxygen species (ROS) can be produced by epithelial as well as phagocytic cells, including neutrophils. ${ }^{4-7}$ Recent studies have shown increased mucosal concentrations of ROS in peptic disorders such as duodenal and gastric ulcer ${ }^{78}$ and inflammatory disorders such as ulcerative colitis and Crohn's disease. ${ }^{9-11}$ In these disorders, the high concentrations of tissue ROS may be responsible, in part, for the tissue injury. Additionally, ROS have been implicated in carcinogenesis and mutagenesis in malignancies of the stomach and colon. ${ }^{12} 13$ Furthermore, Guilianelli et al showed that an iron containing mineral particle, nemalite, causes squamous metaplasia in rabbit primary cultures of tracheal epithelium. ${ }^{14}$ Nemalite produced ROS, as measured by electron spin resonance, and damaged the cell lines. This study shows that ROS are capable of inducing epithelial metaplasia.

Thus, we hypothesise that ROS are present in high concentrations in the Barrett's epithelium and are important factors in the development of oesophageal mucosal tissue injury, metaplastic Barrett's oesophagus, and subsequent oesophageal adenocarcinoma. The purpose of our study, therefore, was to discover if the oesophageal mucosa of patients with oesophagitis and Barrett's oesophagus had increased tissue concentrations of ROS.

\section{Methods}

Subjects

Eighty three consecutive ambulatory outpatients undergoing upper gastrointestinal endoscopy in the outpatient endoscopy clinic between 1 September and 1 December 1993 
TABLE I Demographic characteristics of study groups

\begin{tabular}{|c|c|c|c|c|c|c|c|c|c|}
\hline \multirow[b]{2}{*}{ Group (n) } & \multirow[b]{2}{*}{$\begin{array}{l}\text { Age } \\
\text { (range) }\end{array}$} & \multicolumn{3}{|l|}{ Smoking } & \multicolumn{3}{|l|}{ Alcohol } & \multicolumn{2}{|l|}{$T$ reatme } \\
\hline & & Smoker & $\begin{array}{l}\text { Stopped or } \\
\text { never } \\
\text { smoked }\end{array}$ & $\begin{array}{l}\text { Pack } \\
\text { years } \\
\text { (mean) }\end{array}$ & $\begin{array}{l}\text { Alcohol } \\
\text { abuser }\end{array}$ & $\begin{array}{l}\text { Stopped or } \\
\text { never } \\
\text { drank }\end{array}$ & $\begin{array}{l}\text { Ounce } \\
\text { years } \\
\text { (mean) }\end{array}$ & $\begin{array}{l}\mathrm{H}_{2} \text { receptor } \\
\text { antagonists }\end{array}$ & Omeprazole \\
\hline $\begin{array}{l}\text { I Control (19) } \\
\text { II Oesophagitis (20) } \\
\text { III Inactive Barrett's (20) } \\
\text { IV Active Barrett's (24) }\end{array}$ & $\begin{array}{l}63(47-75) \\
62(47-79) \\
67(37-79) \\
66(43-82)\end{array}$ & $\begin{array}{l}9 \\
6 \\
5 \\
6\end{array}$ & $\begin{array}{l}10 \\
14 \\
15 \\
18\end{array}$ & $\begin{array}{l}50 \\
49 \\
63 \\
32\end{array}$ & $\begin{array}{r}9 \\
13 \\
12 \\
16\end{array}$ & $\begin{array}{r}10 \\
7 \\
8 \\
8\end{array}$ & $\begin{array}{l}206 \\
105 \\
216 \\
179\end{array}$ & $\begin{array}{r}4 \\
7 \\
3 \\
10\end{array}$ & $\begin{array}{l}0 \\
0 \\
0 \\
1\end{array}$ \\
\hline
\end{tabular}

Pack years - number of cigarette packs daily $\times$ number of years. Ounce years - ounces of alcohol daily $\times$ number of years. One ounce was equivalent to (a) one 12 ounce can be beer, (b) one ounce (30 cc) of spirits, or (c) four ounces of wine.

Efforts were made to obtain estimates based on patient recall and chart review.

were included in this study. Four groups of patients were studied (Table I).

Group 1 (control) consisted of 19 male patients with no oesophageal symptoms and a macroscopically normal oesophageal mucosa. These patients received upper gastrointestinal endoscopy as part of a clinical evaluation for a variety of non-reflux related conditions such as abdominal pain, anaemia, unexplained faecal blood, and peptic ulcer disease follow up. Group 2 (oesophagitis without Barrett's) consisted of 20 male patients with erosive oesophagitis. All patients had heartburn and regurgitation. Group 3 (inactive Barrett's) consisted of 20 male patients with previously confirmed Barrett's oesophagus and no macroscopic oesophagitis. These patients received upper gastrointestinal endoscopy either as part of a Barrett's surveillance programme or for evaluation of reflux symptoms. Group 4 (active Barrett's) consisted of 24 male patients with previously confirmed Barrett's oesophagus and macroscopic oesophagitis. These subjects received upper gastrointestinal endoscopy as part of the Barrett's surveillance programme or for evaluation of reflux symptoms.

Barrett's epithelium was defined as the presence of specialised columnar epithelium of any length in the tubular oesophagus. The mean length of Barrett's epithelium was 1.8 $\mathrm{cm}$ (range $<1.0 \mathrm{~cm}$ to $10 \mathrm{~cm}$ ). Tongues of Barrett's less than $2.0 \mathrm{~cm}$ were present in 31 $(70.4 \%)$ patients; tongues greater or equal to $2.0 \mathrm{~cm}$ in six $(13.6 \%)$ patients; and circumferential with or without tongues in seven $(16 \cdot 0 \%)$ patients.

Upper gastrointestinal endoscopy, biopsy, and handling of specimens

All subjects underwent upper gastrointestinal endoscopy using a standard Olympus

TABLE II Endoscopic classification of oesophagitis

Grade 0 - Normal mucosa with no abnormalities

Grade 1 - Erythema or hyperaemia of the oesophageal mucosa, with no macroscopic erosions

Grade 2 - Superficial ulceration or erosions involving $<10 \%$ of the last $5 \mathrm{~cm}$ of the oesophageal squamous mucosal surface

Grade 3 - Superficial ulceration or erosions involving $>10-50 \%$ of the last $5 \mathrm{~cm}$ of the oesophageal squamous mucosal surface

Grade 4 - Deep ulceration anywhere in the oesophagus or confluent erosion of more than $50 \%$ of the last $5 \mathrm{~cm}$ of the oesophageal squamous mucosal surface

Taken from Hetzel et al. ${ }^{15}$ gastroscope. All endoscopies were performed by either of two endoscopists using predefined criteria. Multiple mucosal biopsy specimens were obtained under direct vision from both the distal oesophagus (at the squamocolumnar junction) and the proximal oesophagus. In groups I and II, biopsy samples were taken $1 \mathrm{~cm}$ above the gastro-oesophageal junction and in the proximal oesophagus at $25 \mathrm{~cm}$ from the incisors. In groups III and IV biopsy samples were taken of the Barrett's epithelium from about $1 \mathrm{~cm}$ above the gastrooesophageal junction (if Barrett's segment was less than $2.0 \mathrm{~cm}$ ) and from the centre of the Barrett's if the segment was greater than $2.0 \mathrm{~cm}$; and from the squamous epithelium $25 \mathrm{~cm}$ from the incisors. In addition, specimens were taken of the gastric mucosa from 1-2 cm below the gastro-oesophageal junction.

The oesophageal mucosa was scored from grade 1 to 4 based on the endoscopic (not histological) appearance (Table II) as previously described. ${ }^{15}$ The mucosa was considered normal (control group) if there was no macroscopic oesophagitis (grade 0 ). Oesophagitis was diagnosed if there was any break in the mucosa (erosions or ulcerations, or both) with or without exudate, as seen during endoscopy (grades 2-4). Barrett's oesophagus, with or without oesophagitis, was diagnosed only if there was columnar epithelium of the specialised (intestinal) type, obtained by biopsy from any level of the tubular oesophagus. The presence of columnar epithelium of the gastric type only was not considered to be Barrett's oesophagus. Histological examination of the oesophageal mucosa was used only to establish the presence of Barrett's oesophagus and not the diagnosis of oesophagitis.

Fresh mucosal biopsy specimens were placed in oxygenated Krebs-Ringer buffer and transported to the laboratory for measurement of ROS. A second specimen was placed in formalin saline for subsequent histological analysis.

\section{Luminol enhanced chemiluminescence} (LECL)

Mucosal ROS concentrations were estimated by LECL as previously described by us ${ }^{910}$ by an operator who was unaware of the subject's group. Light was detected by an EMI 9813 B photomultiplier in an EMI FACT $50 \mathrm{MK}$ III cooler, cooled to $-20^{\circ} \mathrm{C}$, and operated at 


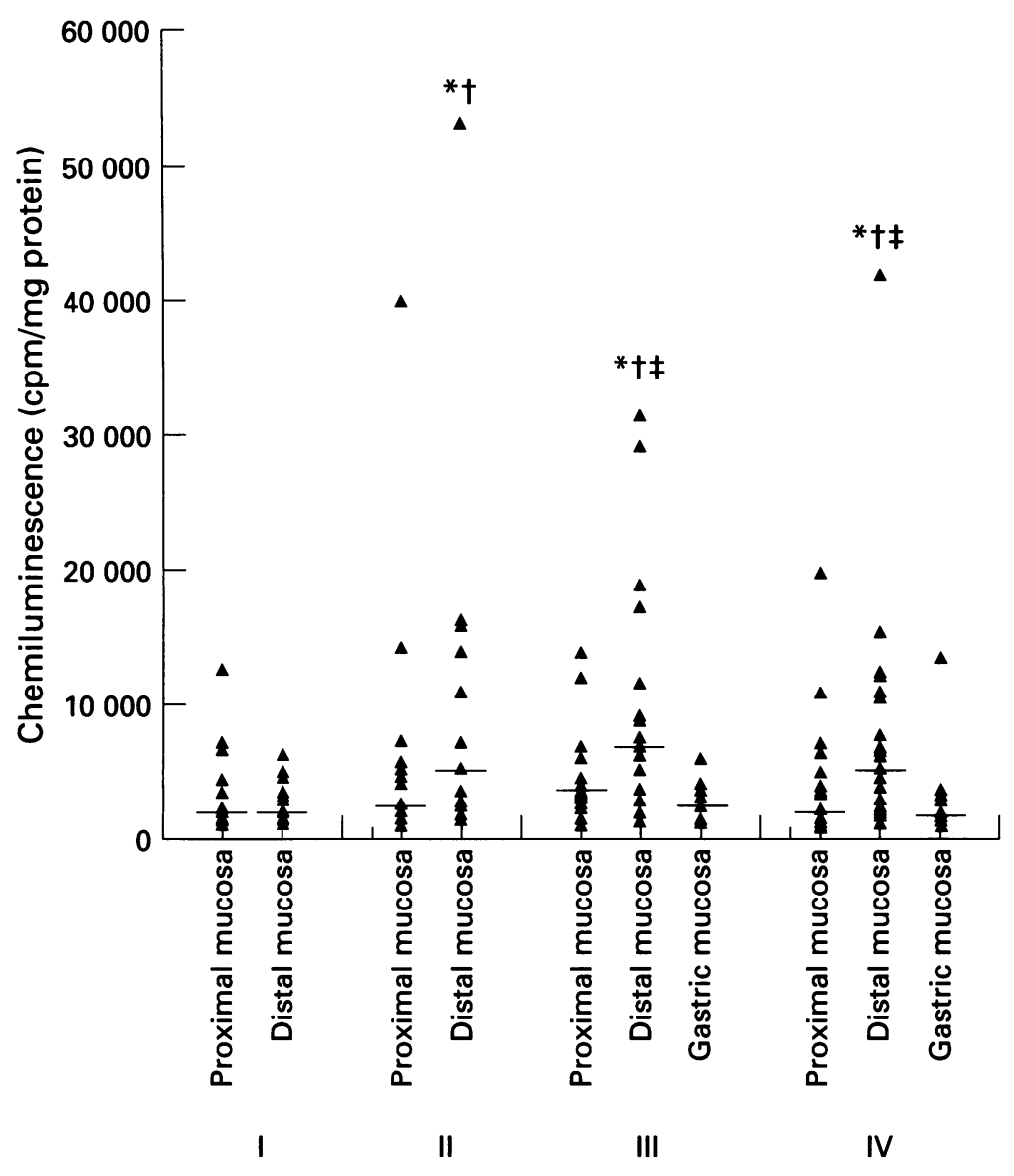

Experimental group

Figure 1: LECL in the proximal, distal oesophageal mucosa and the gastric mucosa. In group I subjects, values of mucosal LECL in the distal oesophageal mucosa were similar to those in the proximal oesophageal mucosa, while groups II, III, and IV patients all had distal LECL values that were significantly higher than those in the proximal oesophageal mucosa. ${ }^{\star}=p<0.05$ proximal $\mathrm{v}$ distal oesophagus; $\dagger=$ distal oesophagus $\mathrm{v}$ control group; $\ddagger=$ distal oesophagus $\mathrm{v}$ gastric. Horizontal line $=$ median. Group I - control (normal oesophageal mucosa); group II - oesophagitis without Barrett's; group III - inactive Barrett's (no macroscopic oesophagitis); group IV-active Barrett's (macroscopic oesophagitis).
Myeloperoxidase activity was measured as previously described. ${ }^{17}$

\section{Statistical analysis}

Analysis of variance and $\chi^{2}$ analysis were used to compare demographic data between groups. The Mann-Whitney $U$ test was used to assess differences in chemiluminescence values between groups. A value for $p$ of less than 0.05 was considered significant. Spearman correlation analysis was used to determine a possible correlation between mucosal chemiluminescence values and other indicators of inflammation.

These studies were approved by the Institutional Review Board for Human Studies at Hines Veterans Affairs Hospital and were performed after written consent.

\section{Results}

All four groups were similar with regard to age, and use of acid inhibiting agents such as omeprazole and $\mathrm{H}_{2}$ receptor antagonists (Table I). There was also no statistically significant differences ( $\chi^{2}$ analysis) between groups with regard to smoking or ethanol abuse.

\section{LECL in the proximal oesophagus}

Median and (mean) values of mucosal LECL (cpm/mg protein) in the proximal oesophageal mucosa of control subjects (1500 (2874)), of oesophagitis without Barrett's patients (1842 (5373)), or inactive Barrett's patients (2925 (4028)), and of active Barrett's patients (1079 (2966)) were not significantly different (Fig 1). There were no significant differences in LECL values between smokers (1684) and non-smokers (2582). Furthermore, there was no significant correlation between packs/year smoking and LECL values $(r=0.12)$ in smokers. Similarly, there was no significant difference in LECL values between smokers and non-smokers in each of the four groups. Alcoholism also had no significant effect on mucosal LECL values.

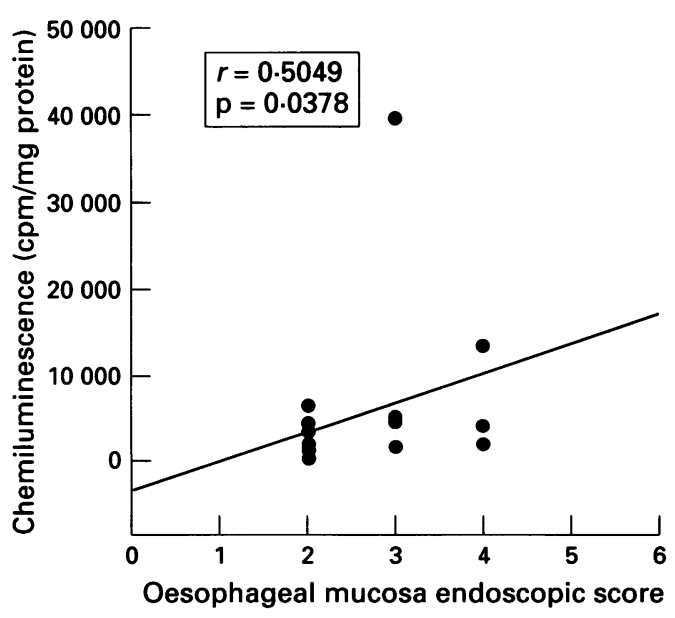

Figure 2: Correlation between mucosal LECL values and the severity of oesophagitis in patients with oesophagitis. There was a modest but significant correlation found between mucosal LECL values and oesophageal mucosa endoscopic score in patients with oesophagitis. 
There was no significant difference in LECL values between heavy drinkers and nondrinkers. There was no correlation $(r=0.04)$ between ethanol consumption and LECL values.

\section{LECL in the distal oesophagus}

In control subjects, median (mean) values of mucosal LECL in the distal oesophageal mucosa (1257 (1951)) were similar to those in the proximal oesophageal mucosa (Fig 1). In contrast, patients with oesophagitis without Barrett's (4436 (9708)), inactive Barrett's (6022 (8638)), and active Barrett's (4500 (6390)) all had mucosal LECL values that were significantly higher than the values in the proximal oesophageal mucosa (Fig 1). Furthermore, there was a significant $(p=0.037)$ correlation between mucosal LECL values and the severity of oesophagitis in patients with oesophagitis ( $r=0.51$, Fig 2$)$.

Values of mucosal LECL in the distal oesophageal mucosa of patients with Barrett's oesophagus, regardless of the presence of oesophagitis, were significantly higher than those in control mucosa (Fig 1). Additionally, in patients with Barrett's oesophagus, LECL values in the distal oesophageal mucosa were significantly higher than those in gastric mucosa in patients without $(1850$ (2020)) and with (1245 (2080)) endoscopic oesophagitis (Fig 1).

Neither smoking or alcohol abuse had significant effects on LECL values in any of the four groups. Mucosal LECL values in smokers (2838) were not significantly different from values in non-smokers (4240). Additionally, there was no significant correlation $(r=0.03)$ between pack years smoking and LECL. Similarly, mucosal LECL values in heavy drinkers (4166) were similar to non-alcoholic subjects (2500).

\section{Effect of inhibitors on mucosal chemiluminescence}

Azide, a specific myeloperoxidase enzyme inhibitor at $100 \mu \mathrm{M}$, and catalase, a hydrogen peroxide scavenger, both decreased the LECL values (mean (SEM)) in the distal oesophageal mucosa by $31.8(6.5) \%, n=13$ and 44.6 $(13.3) \%, n=11$, respectively. These results suggest that in patients with oesophagitis and Barrett's oesophagus, less than $50 \%$ of mucosal chemiluminescence originates from mucosal granulocytes.

\section{Myeloperoxidase concentrations in the oesophageal mucosa}

As expected, myeloperoxidase concentrations ( $\mathrm{mg}$ protein) were increased in the distal oesophageal mucosa in patients with oesophagitis $(113.6(41 \cdot 7), \mathrm{n}=9$, mean $(\mathrm{SEM}))$, inactive Barrett's $(148 \cdot 2(42 \cdot 7)$, $\mathrm{n}=12)$, and active Barrett's (221.7 (80), $\mathrm{n}=13)$ when compared with controls $(59 \cdot 3$ $(15 \cdot 4), n=8)$. There was no significant correlation between mucosal LECL values and myeloperoxidase values $(r=0 \cdot 17$, $\mathrm{p}=0 \cdot 29)$.

\section{Discussion}

The initiating factor for development of oesophagitis and Barrett's oesophagus is reflux of gastric contents into the oesophagus. ${ }^{2}{ }^{3}$ The most probable injurious factor is gastric acid, ${ }^{18-20}$ but other compounds such as bile acids and pancreatic enzymes have also been implicated. ${ }^{21-24}$ Regardless of the initiating factor, inflammatory mediators such as ROS can play an important part in maintaining the inflammatory process and subsequent tissue damage.

ROS have indeed been implicated as an important factor in tissue damage in a variety of diseases. ${ }^{25} 26$ ROS can be produced by phagocytic cells, including neutrophils ${ }^{4-6}$ and epithelial cells. ${ }^{7}$ In inflammatory disorders such as ulcerative colitis and Crohn's disease, ROS can either initiate or sustain the inflammatory process, which in turn can result in tissue damage. ${ }^{9102728}$ Hence, in oesophageal disorders, ROS can participate in oesophageal mucosal damage by maintaining the inflammatory processes.

Our data clearly show that mucosal ROS concentrations are increased in patients with oesophagitis and Barrett's oesophagus. Our results can only suggest but cannot prove a pathogenetic role of ROS. It is not unreasonable to speculate, however, that ROS are involved in the damage to the oesophageal mucosa. A positive and significant correlation between mucosal chemiluminescence values and the severity of oesophagitis support this hypothesis.

One potentially useful method that may show a pathogenetic role for ROS in the development of oesophagitis is the prevention of mucosal damage or promotion of mucosal healing, or both, by addition of antioxidant agents. The combination of catalase (a hydrogen peroxide scavenger) and superoxide dismutase did not affect experimentally induced oesophagitis in animals. ${ }^{29}$ It is important to note, however, that catalase and superoxide dismutase are poorly absorbed and have limited tissue penetration. The lack of response to these compounds, therefore, does not exclude a possible role for ROS in oesophagitis. Further studies on the use of more suitable antioxidants in human oesophagitis are needed.

Our study did not identify the exact source of oesophageal mucosa ROS. It did, however, suggest that neutrophils are not the sole source of ROS in oesophagitis and Barrett's oesophagus, as azide and catalase only partially inhibit ROS values. In contrast, azide and catalase inhibited more than $80 \%$ of mucosal ROS values in ulcerative colitis. ${ }^{910}$ Moreover, there was no significant correlation between mucosal myeloperoxidase concentrations, a sensitive index of mucosal polymorphonuclear neutrophil infiltration, and mucosal chemiluminescence values. None the less, our data suggest that polymorphonuclear neutrophils 
are still an important source of mucosal ROS, as a myeloperoxidase enzyme inhibitor, azide, inhibited mucosal ROS concentrations. It should be pointed out, however, that our data do not necessarily indicate that oesophageal mucosa LECL is myeloperoxidase dependent, as azide can also inhibit other haemoproteins and can scavenge singlet oxygen. ${ }^{30-32}$ Azide at concentrations less than $100 \mu \mathrm{M}$, however, which we used in our experiments, seems to be a specific myeloperoxidase inhibitor. ${ }^{30-32}$ Hence, it seems that at least one third of the ROS in the inflamed oesophageal mucosa originates from mucosal granulocytes.

Our biochemical findings in Barrett's oesophagus and oesophagitis are consistent with well established histological findings in that only a limited number of infiltrated neutrophils are present in the mucosa of patients with oesophagitis. ${ }^{33} 34$ In fact, our myeloperoxidase data suggested that although neutrophils are present in the inflamed Barrett's oesophagus and oesophagitis, the magnitude of infiltration is significantly less than would be normally seen in patients with ulcerative colitis. ${ }^{10}$

As the oesophageal mucosa contains enzymes such as xanthine oxidase, ${ }^{35}$ which is capable of producing ROS, it is not unreasonable to suggest that epithelial cells are an important source of mucosal ROS in oesophagitis. Indeed, in such diseases as reperfusion ischaemic injury of the small intestine, ${ }^{7}$ the ROS that result in tissue injury are produced by the epithelial cells. It is therefore not surprising that ROS concentrations are increased in oesophagitis and Barrett's oesophagus. Other sources of ROS, such as endothelial cells and mucosal macrophages, should also be considered.

We found that both myeloperoxidase activity and ROS production were increased in endoscopically uninflamed distal oesophageal mucosa in patients with Barrett's oesophagus. These findings show the lack of reliability and low sensitivity of the endoscopic appearance for diagnosing oesophageal injury. Our findings are consistent with previous experience that also showed a low sensitivity for normal appearing oesophageal mucosa in assessing the presence of oesophagitis. ${ }^{34}$

The potential importance of ROS in carcinogenesis in Barrett's oesophagus is intriguing, especially as ROS can result in damage to DNA. ${ }^{1336}$ Indeed, ROS have been implicated as a carcinogenic factor in various malignant disorders including colon cancer. ${ }^{1213}$ Thus, increased concentrations of ROS may play a part in carcinogenesis of Barrett's oesophagus. Our study was not designed to show a difference in ROS values between the benign condition of oesophagitis and the premalignant condition of dysplastic Barrett's epithelium. As none of our patients with Barrett's oesophagus had high grade dysplasia, the lack of significant difference in mucosal chemiluminescence values between patients with Barrett's epithelium and those with oesophagitis should not be interpreted to mean that ROS do not play an important carcinogenic part in Barrett's epithelium. Further studies are needed in patients with Barrett's and high grade dysplasia to answer these questions.

In conclusion, our data suggest that ROS may play a part in the tissue injury of oesophagitis and Barrett's oesophagus. The contribution of ROS to carcinogenesis in Barrett's epithelium remains to be shown.

The authors are grateful to Ms Jean Seidel and Ms Heidi Heintz for preparing this manuscript. The data were presented in part at Digestive Disease Week 1993 and published in abstract form in Gastroenterology 1993; 104: A778.

1 Schnell T, Sontag S, Wanner J, Chintam R, Cheifec G, O'Connell $S$, et al. Endoscopic screening for Barrett's esophagus, esophageal adenocarcinoma and other mucosal changes in ambulatory subjects with symptomatic gastroesophageal reflux. Gastroenterology 1985; 88: A1576.

2 Dent J, Dodds WJ, Friedman RH, Sekiguchi T, Hogan WJ, Arndorfer RC, et al. Mechanism of gastroesophageal reflux in recumbent asymptomatic human subjects. $\mathcal{f}$ Clin Invest 1980; 65: 256-7.

3 Dodds WJ, Dent J, Hogan WJ, Helm JF, Hauser R, Patel $\mathrm{GK}$, et al. Mechanisms of gastroesophageal reflux in patients with reflux esophagitis. $N$ Engl $₹$ Med 1982; 307: patients $1547-52$.

4 McCord JM, Fridovich I. The biology and pathology of oxygen radicals. Ann Intern Med 1978; 89: 121-7.

5 Buckley GB. The role of oxygen free radicals in human disease processes. Surgery 1983; 94: 407-11.

6 Fantone JC, Ward PA. Role of oxygen-derived free radicals and metabolites in leukocyte-dependent inflammatory reactions. Am $\mathcal{F}$ Pathol 1982; 107: 397-418.

7 Parks D, Buckley G, Granger N. Role of oxygen-derived free radicals in digestive tract disease. Surgery 1983; 94: free radical 22 .

8 Davies GR, Simmonds NJ, Stevens TRJ, Grandison A, Blake DR, Rampton DS. Mucosal reactive oxygen metabolite production in duodenal ulcer disease. Gut 1992; 33: 1467-72.

9 Keshavarzian A, Sedghi S, Kanofsky J, List T, Robinson C, Ibrahim $\mathrm{C}$, et al. Excessive production of reactive oxygen metabolites by inflamed colon: analysis by chemiluminescence probe. Gastroenterology 1992; 103: 177-85.

10 Sedgi S, Klamut M, Field JL, Urban G, Durkin M, Winship $\mathrm{D}$, et al. Increased production of luminol enhanced $\mathrm{D}$, et al. Increased production of luminol enhanced patients with ulcerative colitis. Gut 1993; 34: 1191-7.

11 Simmonds NJ, Allen R, Stevens TRJ, Van SoMelen RN, Blake DR, Rampton DS. Chemiluminescence assay of mucosal reactive oxygen metabolites in inflammatory bowel disease. Gastroenterology 1992; 103: 186-96.

12 Keshavarzian A, Zapeda D, List T, Mobarhan S. High levels of reactive oxygen metabolites in colon cancer tissue: analysis by chemiluminescence probe. Nutr Cancer 1992; 17: 243-9.

13 Babbs CFC. Free radicals and the etiology of colon cancer. Free Radical Biol Med 1990; 8: 191-200.

14 Guilianelli C, Baeza-Squiban A, Boisvieux-Ulrich E, Houcine O, Zalma R, Guennou C, et al. Effect of mineral particles containing iron of primary cultures of rabbit tracheal epithelial cells: possible implication of oxidative stress. Environ Health Perspect 1993; 101: 436-42.

15 Hetzel DJ, Dent J, Reed WD, Narielvala FM, Mackinnon $\mathrm{M}$, McCarthy $\mathrm{JH}$, et al. Healing and relapse of severe peptic esophagitis after treatment with omeprazole. Gastroenterology 1988; 95: 903-12.

16 Bradford MM. A rapid and sensitive method for the quantitation of microgram quantities of protein utilizing the principle of protein-dye binding. Anal Biochem 1976; 72: 248-54.

17 Bradley PP, Priebat DA, Christenson RD, Rothstein G. Measurement of cutaneous inflammation: estimation of neutrophil content with an enzyme marker. $\mathcal{f}$ Invest Dermatol 1982; 78: 206-9.

18 Goldberg HI, Dodds WJ, Gee S, Montgomery C, Zboralske FF. Role of acid and pepsin in acute experimental esophagitis. Gastroenterology 1969; 56: 223-30.

19 Hendrix TR, Yardley JH. Consequences of gastroesophageal reflux. Clin Gastroenterol 1976; 5: 155-74.

20 Demeester TR, Johnson LF, Joseph GJ, Toscano MS, Hall AW, Skinner DB. Patterns of gastroesophageal reflux in health and disease. Ann Surg 1976; 184: 459-69.

21 Cross FS, Wangensteen OH. Role of bile and pancreatic juice in production of esophageal erosions and anemia. Proc Soc Exp Biol Med 1957; 77: 862-6.

22 Helsinger N. Esophagitis following total gastrectomy. Acto Chir Scand 1959; 118: 190-201.

23 Palmer ED. Subacute erosive esophagitis associated with achlorhydria. N Engl f Med 1960; 161: 927-9.

24 Safaie-Shirazi S, DenBesten L, Ziek WO. Effect of bile salts on the ionic permeability of the esophageal mucosa and their role in the production of esophagitis. Gastroenterology their role in the produ
$1975 ; 68: 728-33$. 
25 Weiss SJ. Tissue destruction by neutrophils. $N$ Engl $\mathcal{F}$ Med 1989; 320: 365-76.

26 Simmonds NJ, Rampton DS. Inflammatory bowel disease. A radical view. Gut 1993; 34: 1174-80.

27 Harris ML, Schiller HJ, Reilly PM, Donowitz M, Grisham MB, Bulkley GB. Free radicals and other reactive oxygen metabolites in inflammatory bowel disease: cause, consemetabolites in inflammatory bowel disease: cause, consequence or $375-408$.

28 Keshavarzian A, Morgan G, Sedghi S, Gordon JH, Doria $M$. Role of reactive metabolites in experimental colitis. Gut 1990; 31: 786-90.

29 Stein BE, Grenwald LL, Carroll MA, Hodgeson JB, Rosenthal WS. Role of oxygen radicals in esophageal mucosal injury. Clin Res 1987; 35: 798A.

30 Dahlgren C, Stendahl O. Role of myeloperoxidase in luminol dependent chemiluminescence of human neutrophils. Infect Immun 1983; 39: 736-41.

31 Dechatelet LR, Long GD, Shirley PS, Bass DA, Thomas
MJ, Henderson FW, et al. Mechanism of the luminoldependent chemiluminescence of human neutrophils. f Immunol 1982; 129: 1589-93.

32 Klebanoff SJ, Pincus SH. Hydrogen peroxide utilization in myeloperoxidase-deficient leukocytes: a possible microbicidal control mechanism. $f$ Clin Invest 1971; 50: 2226-9.

33 Ismail-Beigi F, Horton PF, Pope CE II. Histological consequences of gastroesophageal reflux in man. quences of gastroesophageal

34 Johnson LF, DeMeester TR, Haggitt RC. Esophageal epithelial response to gastroesophageal reflux. A quantitative study. Dig Dis Sci 1978; 23: 498-609.

35 Stanley JS, York JL, Benson AM. Nitroreductases and glutathione transferases that act on 4-nitroquinoline 1-oxide and their differential induction by butylated hydroxyanisole in mice. Cancer Res 1992; 52: 58-63.

36 Moody CS, Hassan HM. Mutagenicity of oxygen-free radicals. Proc Natl Acad Sci USA 1982; 79: 2855-9. 